\title{
Como Ferramentas de Modelagem de Distribuição de Espécies Podem Subsidiar Ações de Governo?
}

\author{
How Can Species Distribution Modeling Tools Support Government Actions?
}

\author{
Natália Mundim Tôrres ${ }^{1,2 *}$ \& Ugo Eichler Vercillo ${ }^{3}$
}

\author{
${ }^{1}$ Programa de Pós-graduação em Ciências Ambientais, Universidade Federal de Goiás - UFG, CEP 74001-970, \\ Goiânia, GO, Brasil \\ ${ }^{2}$ Instituto Onça-Pintada/Jaguar Conservation Fund, CEP 75830-000, Mineiros, GO, Brasil \\ ${ }^{3}$ Instituto Chico Mendes de Conservação da Biodiversidade - ICMBio, CEP 70670-350, Brasilia, DF, Brasil
}

Já não é novidade o reconhecimento de que em uma escala global, as maiores ameaças à biodiversidade decorrem da crescente ocupação das paisagens naturais por atividades antrópicas, sendo que a remoção dos hábitats naturais e a formação de fragmentos menores e isolados são as consequências diretas dessa ocupação (Foley et al. 2005). Além desses fatores, mudanças climáticas globais causadas por atividades antrópicas têm sido sugeridas como responsáveis potenciais por alterações significativas nas distribuições das espécies, podendo atuar como uma causa relevante de sua extinção em um futuro próximo (Thomas et al. 2004).

Nesse contexto, um dos problemas enfrentados pelos conservacionistas no sentido de reverter os efeitos dessas ameaças é identificar de maneira rápida e barata as áreas mais importantes para a conservação da biodiversidade e apresentar aos tomadores de decisão informações relevantes que sejam capazes de orientar as políticas públicas.

Essa busca é geralmente comprometida pelo fato de que os dados em escalas mais precisas de distribuição dos organismos são escassos e muito caros para serem adquiridos em quantidades suficientes e de maneira sistemática (Ottaviani et al. 2004).Esse cenário é ainda mais preocupante ao considerarmos a crescente demanda de uso e ocupação do solo, que requer o posicionamento imediato dos tomadores de decisão, os quais não podem decidir com base na ausência de informações.

Sendo assim, os conservacionistas e tomadores de decisão têm o desafio de identificar áreas importantes e estabelecer estratégias para a conservação da biodiversidade, ainda que

\footnotetext{
*Autor para correspondência: Natália Mundim Tôrres Programa de Pós-graduação em Ciências Ambientais, Universidade Federal de Goiás - UFG, Campus Samambaia (Campus II), CP 131, CEP 74001-970, Goiânia, GO, Brasil

E-mail: nats.torres@jaguar.org.br
}

com dados incompletos, antes que as alterações geradas pelo desenvolvimento exterminem as espécies. Para isto, o conhecimento sobre a distribuição geográfica das espécies é de fundamental importância (Margules \& Pressey 2000).

Modelos de distribuição geográfica de espécies (ou em inglês Species Distribution Modeling - SDM) se desenvolveram de forma expressiva nos últimos anos devido à disponibilidade de dados climatológicos e ecológicos em largas escalas espaciais, em conjunto com a facilidade de acesso a Sistemas de Informação Geográfica, programas de otimização e maior poder computacional. O emprego desses modelos, que predizem a distribuição espacial potencial baseado nos requerimentos ecológicos das espécies, extrapolando para áreas desconhecidas a partir de pontos conhecidos, pode ser utilizado como base para vários tipos de análises e avaliações. Dentre elas, conhecer a situação de reservas naturais e indicar o estabelecimento (melhorando o planejamento) de novas unidades de conservação; guiar pesquisas de maneira mais eficiente; orientar processos de licenciamento, de forma a minimizar impactos humanos; prever os efeitos de mudanças climáticas globais; indicar áreas para a restauração de hábitats e reintrodução de espécies ou auxiliar no manejo de espécies invasoras.

Por serem reconhecidos como simplificações de uma realidade complexa e difícil de ser compreendida, os resultados dos modelos devem ser interpretados e aplicados com cautela, considerando suas limitações, como por exemplo, a incapacidade de modelar interações bióticas, padrões de dispersão ou mudanças evolutivas. De toda forma, a modelagem de distribuição de espécies é considerada hoje a ferramenta mais avançada para estudos de distribuição em larga escala (Franklin 2009),sendo extremamente úteis para orientar tomadas de decisão e implementação de medidas de gestão por parte do governo. Assim, são de grande valia para a sociedade ao reduzir a subjetividade 
da análise e consequentemente, direcionar melhor as exigências dos estudos de impacto ambiental feitas pelos órgãos licenciadores ao empreendedor e aperfeiçoar as medidas mitigadoras compensatórias estabelecidas nas emissões das licenças ou autorizações ambientais.

No caso de seleção de reservas, tem sido demonstrado que agir guiado pela ignorância e oportunismo pode ser mais caro do que agir com o apoio de dados e modelos (Pressey \& Cowling 2001). Ainda, planos de conservação em grandes escalas devem se basear no conhecimento da distribuição passada e presente da espécie em questão, assim como na distribuição dos impactos existentes sobre as populações. Prever onde espécies podem sofrer com as consequências da fragmentação, por exemplo, pode permitir que tomadores de decisão atuem de maneira proativa, conservando regiões chave para a manutenção da conexão antes que o desenvolvimento iminente torne os custos com a conservação proibitivos nessas áreas (Ahern 1995).

No entanto, apesar da ampla utilização de SDM em estudos realizados nos últimos anos, tanto internacionalmente quanto no Brasil, poucos são os trabalhos desenvolvidos em consonância com tomadores de decisão, objetivando a aplicação destes modelos como subsídio para estratégias de conservação. Existem algumas possíveis explicações para esta falta de intercâmbio entre o que vem sendo produzido no meio acadêmico e os responsáveis pela gestão pública em nosso país.

A primeira delas pode estar relacionada à dificuldade aparentemente crônica dos pesquisadores em reverter os resultados obtidos em seus estudos em uma linguagem clara e didática o suficiente para que os gestores públicos os compreendam e consigam aplicá-los de maneira prática em suas decisões. Aliado a isto, existe uma expressiva diferença no perfil, linguagem, jargões e preconcepções entre estes dois grupos que maximiza ainda mais esta lacuna de comunicação. Esta problemática foi discutida com propriedade por Scarano \& Martinelli (2010) em seu artigo a respeito da falta de aceitação por parte da comunidade científica da lista brasileira de espécies da flora ameaçadas de extinção, publicada em setembro de 2008. Os autores citam que na literatura os problemas de comunicação entre cientistas e tomadores de decisões estão relacionados a três diferenças fundamentais entre eles: 1) suas prioridades ou foco de trabalho; 2) sua linguagem ou cultura; e 3) a escala temporal na qual precisam atuar.Em termos de escala temporal de trabalho, o que claramente se observa é que a comunidade científica atua em um ritmo muito mais lento do que o dos gestores públicos, que constantemente necessitam tomar decisões imediatas (Scarano \& Martinelli 2010), ainda mais considerando o atualmomento de crescimento econômico e necessidade de ampliar a capacidade produtiva do país.

Ainda que estas divergências sejam uma constante entre o "mundo acadêmico" e o "mundo real dos gestores públicos", algumas iniciativas pontuais têm sido realizadas no sentido de promover este importante intercâmbio.
O Instituto Chico Mendes de Conservação da Biodiversidade (ICMBio) e pesquisadores especializados em modelagem de distribuição realizaram recentemente um estudo com o objetivo de avaliar a representatividade de espécies da fauna ameaçada de extinçãono Sistema Nacional de Unidades de Conservação (SNUC) e analisar o impacto de empreendimentos estabelecidos e planejados em suas áreas de distribuição, com a finalidade de indicar áreas e ações que sejam prioritárias para a sua conservação.

Os resultados dessa avaliação demonstraram que para o grupo analisado de 192 espécies de vertebrados ameaçados de extinção (anfíbios, répteis, aves e mamíferos), 45 (23\%) encontram-se "protegidas" pelo atual SNUC, segundo as metas adotadas. Porém, a maioria das espécies (114; $59 \%$ ) foi considerada como "parcialmente protegida", tendo apenas uma porção de sua distribuição potencial sobreposta a unidades de conservação. Ainda, 33 (17\%) das espécies analisadas podem ser consideradas como "lacunas", ou seja, sem representação suficiente de suas áreas de distribuição no SNUC (a Figura 1a, b, c ilustra os mapas de riqueza desses grupos de espécies). Foi indicado ainda que as regiões mais importantes para o cumprimento das metas de conservação (de proteger a totalidade das espécies listadas como ameaçadas de extinção) estão localizadas em partes da Mata Atlântica, Caatinga e Pampa.

Esse cenário torna-se ainda mais preocupante ao ter sido verificado que boa parte dos empreendimentos planejados para os próximos anos se sobrepõe a essas regiões de maior importância para as espécies atualmente ameaçadas de extinção. Para os empreendimentos planejados, observam-se algumas zonas de maior conflito na Mata Atlântica, Cerrado e Amazônia (especialmente na região denominada "Arco do Desmatamento"), as quais devem ser consideradas como prioritárias para a conservação, e cujos empreendimentos necessitam especial atenção quanto aos seus processos de licenciamento. Nestes casos, são necessárias avaliações mais detalhadas a respeito de quais espécies estariam sendo impactadas e de que maneira esse impacto pode prejudicá-las em uma escala local/regional.

Resta ainda realizar avaliações mais detalhadas considerando também as alterações que as distribuições geográficas das espécies devem sofrer frente às mudanças climáticas globais. Essas análises são de extrema importância no sentido de possibilitar uma avaliação comparativa entre os empreendimentos, indicando quais apresentam os maiores riscos para a perda de biodiversidade e quais espécies são mais afetadas para que os tomadores de decisão possam ter subsídios claros para promover o desenvolvimento do país com um menor impacto ambiental.

Fica evidente, portanto, o caráter desafiador desse tipo de análise considerando a escala continental de nosso país, o expressivo número de espécies da fauna que ocorrem aqui e a amplitude dos impactos gerados pelos empreendimentos.O uso destas ferramentas pode favorecer o processo de instalação e operação de empreendimentos protegendo áreas importantes para a manutenção da biodiversidade, mas ao mesmo tempo compatibilizando com o desenvolvimento econômico. 


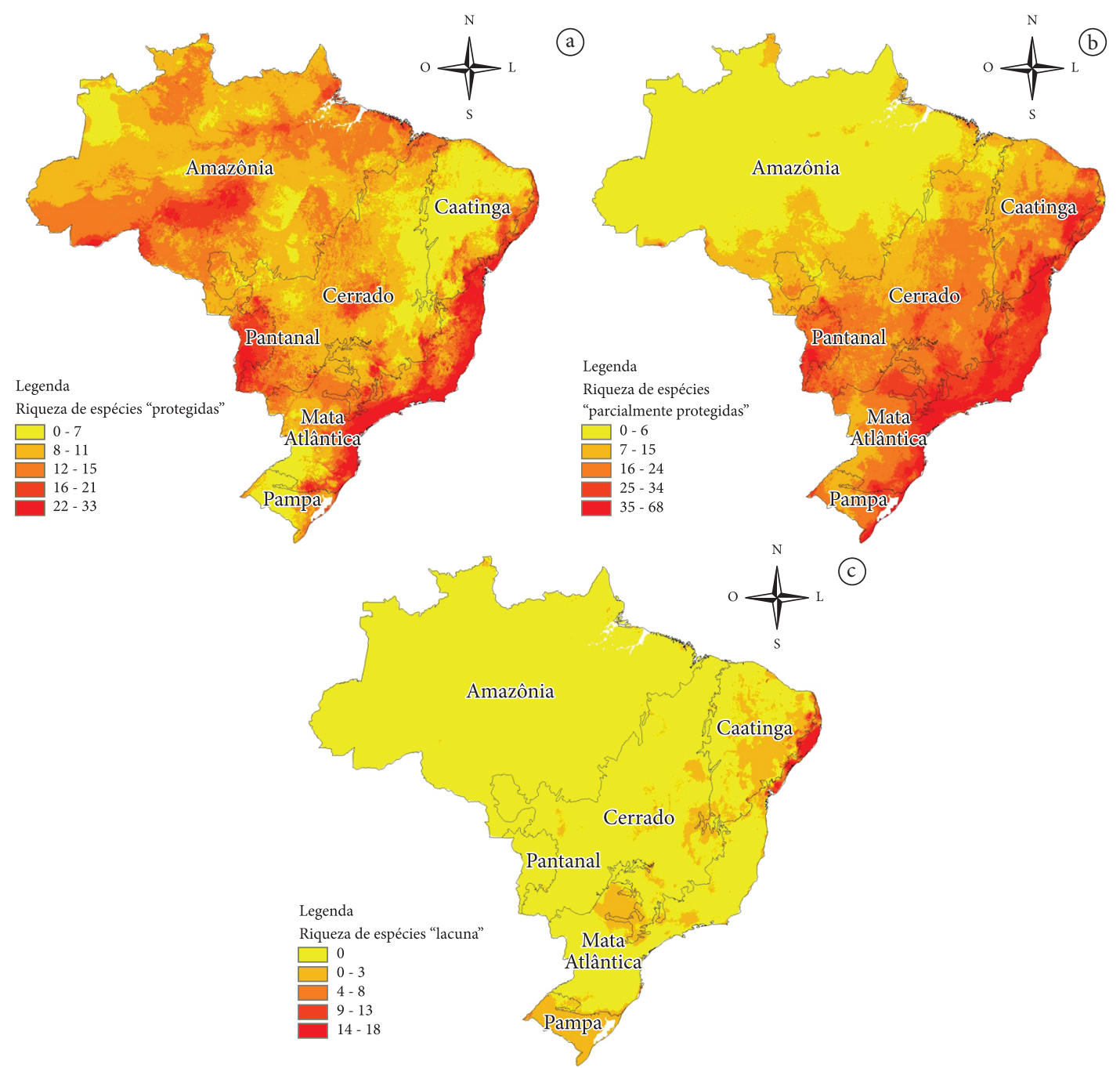

Figura 1. Riqueza potencial das espécies ameaçadas de extinção da fauna brasileira para os grupos anfíbios, répteis, aves e mamíferos, consideradas como "protegidas" (a), "parcialmente protegidas" (b) e "lacunas" (c) pelo atual Sistema Nacional de Unidades de Conservação (SNUC), segundo modelos de distribuição potencial gerados pelo Maxent.

\section{Referências}

Ahern J, 1995. Greenways as a planning strategy. Landscape Urban Planning, 33:131-155. http://dx.doi. org/10.1016/0169-2046(95)02039-V

Foley JA et al., 2005. Global consequences of land use. Science, 309:570-574. PMid:16040698. http://dx.doi. org/10.1126/science. 1111772

Franklin J, 2009. Mapping Species Distributions: Spatial Inference and Prediction. Cambridge: Cambridge University Press.

Margules CR \& Pressey RL, 2000. Systematic conservation planning. Nature, 405:243-253. PMid:10821285. http:// dx.doi.org/10.1038/35012251
Ottaviani D, Lasinio GJ \& Boitani L, 2004. Two statistical methods to validate habitat suitability models using presenceonly data. Ecological Modeling, 179:417-443. http://dx.doi. org/10.1016/j.ecolmodel.2004.05.016

Pressey RL \& Cowling RM, 2001. Reserve selection algorithms and the real world. Conservation Biology, 15:275-277. http:// dx.doi.org/10.1111/j.1523-1739.2001.99541.x

Scarano FR \& Martinelli G, 2010. Brazilian List of Threatened Plant Species: Reconciling Scientific Uncertainty and Political Decision-Making. Natureza \& Conservação, 8(1):13-18. http://dx.doi.org/10.4322/natcon.00801002

Thomas CD et al., 2004. Extinction risk from climate change. Nature, 427:145-148. PMid:14712274. http://dx.doi. org/10.1038/nature02121 